\title{
UNA REFLEXIÓN SOBRE LA EXPULSIÓN DE LOS MORISCOS VALENCIANOS Y LA REPOBLACIÓN
}

\author{
MANUEL ARDIT \\ Universitat de València
}

Fecha de recepción: noviembre 2008

Fecha de aceptación: abril 2009

La expulsión de los moriscos ha sido, especialmente en el País Valenciano, un tema historiográfico que ha estado fuertemente condicionado por presupuestos ideológicos que han llevado a la adopción de percepciones divergentes e incluso enfrentadas. Los contemporáneos del suceso, o al menos aquellos cuyos escritos han llegado hasta nosotros (los críticos valencianos de la medida expulsionista, si los hubo, quizás no pudieron expresarse) alabaron la decisión. He encontrado un texto, obra de Jaume Bendicho, gobernador del marquesado de Llombai en los años cuarenta del siglo XVII, que puede considerarse representativo. Jaume Bendicho era alicantino y quizás fuera hermano de Vicente, conocido autor, entre otras obras, de la Chrónica de la Muy Ilustre, Noble y Leal ciudad de Alicante escrita en 1640. El gobernador del marquesado escribía el año 1643: «En lo any de la nativitat de nostre señor Jesucrist MDCIX, regnant en Espanya Phelip, tercer en Castella y en la Corona de Aragó segon, avent tengut moltes y diverses juntes de perlats per a veure lo modo com se podía posar remei en los grans crims y delictes que cada dia perpetraven los nous convertits en lo present regne, axí contra les magestats divina y humana, com encara contra los cristians vells del dit regne, ab madura delliberació, aprés de aver constat de diversos crims, maleficis y fets d'ells uno y molts procesos justicants (sic) la execució, en 22 de setembre se publicà bando per tot lo present regne que los moros e nous convertits dins 6 dies ixquessen del regne.» ${ }^{1}$

Bendicho justificaba la expulsión por los crímenes y delitos de los nuevos convertidos, pero otros autores alababan la medida, además de por esta razón, porque pensaban que los moriscos no eran un elemento productivo muy activo $y$, por tanto, su

1. AHN: Nobleza, Osuna, leg. 589, 9, s. f. 
extrañamiento no iba a ocasionar consecuencias económicas negativas. Jaime Bleda argumentaba, después de la expulsión que «aquella triste gente eran malos labradores y trabajadores para tierras de secano y las más estavan yermas en sus lugares. No curavan de plantarlas de árboles ni de viñas; sólo andavan ocupados en cultivar sus huertas y jardines que regavan, las quales tenían divididas en pequeños pedaços; y les tomava el coraçón aver de trabajar en un campo ancho y grande. No perseveravan en la labor todo el día sino dos, tres o quatro horas. Eran naturalmente amigos de la ociosidad y muy floxos por lo mal que comían y bevían; si para sembrar la tierra avía de ararse seys o siete veces, ellos se contentaban con ararla tres o quatro, y essas fuera de tiempo. $»^{2}$ Podemos encontrar opiniones semejantes en otros autores de la época, como el aragonés Damián Fonseca ${ }^{3}$. Esta opinión aparece también en algunos textos que reflejan un punto de vista aparentemente común entre la población cristiana. Ximénez de Reinoso, inquisidor de Valencia, escribía en 1582 que «ordinariamente, y se tiene experiencia dello, una casa de cristiano viejo a menester para su sustentación tanto como dos casas de moriscos. $»^{4}$ Conocemos muchos pasajes parecidos del que parece que era un tópico entre la población cristiana, como aquél de un comisario del duque de Gandía durante la repoblación, que advertía que «el morisco se contentava con dos hanegadas de tierra y se tenía rico con ellas... y agora a los nuevos pobladores se les da a quince hanegadas de huerta a cada uno y aún no se tienen por contentos. $\gg^{5} \mathrm{La}$ opinión mayoritaria entre los cristianos viejos era que los moriscos eran agricultores poco eficientes y pobres, cultivadores de pequeñas huertas destinadas al autoconsumo y que no atendían a los cultivos comerciales. Quizás se trataba de minimizar las consecuencias de la expulsión y algunos incluso pensaban que con la mitad de los efectivos moriscos podía considerarse completa la repoblación.

Otro tópico era el de la superpoblación morisca o si se quiere, con más exactitud, el del superior crecimiento vegetativo de la población islámica. Martín de Salvatierra, obispo de Segorbe, por ejemplo, se atemorizaba el año 1587 porque «en breves años se multiplicarán de tal manera que sobrepujen mucho a los christianos viejos, así en número de personas como en cantidad de hacienda, specialmente de oro y plata, porque lo ban recogiendo todo y no lo gastan, pues no comen ni veven ni visten ni calçan. ${ }^{6}$ En esta misma línea, un informe elevado al monarca el año 1607 por la Junta de Tres, decía que «porque al paso que los christianos viejos van menguando, así por los muchos que se meten de religión y van muriendo de enfermedades y trabajos, como por la saca que ay de continuo para la guerra y Yndias, y los excesivos gastos que se an yntroducido con las cargas del matrimonio, que por no obligarse a ellos dexan

2. BledA, Jaime: Corónica de los moros de España, València: Felipe Mey, 1618, pp. 1.030-1.031.

3. FonsECA, Damián: Justa expulsión de los moriscos de España, Roma: Iacomo Mascardo, 1612, p. 323.

4. Texto reproducido por BORONAT, Pascual: Los moriscos españoles y su expulsión. Estudio históricocrítico, 2 vols., Valencia: Francisco Vives Mora, 1901, I, pp. 596-597.

5. Reproducido por CASEY, James: «Què deu el País Valencià als canvis en el poblament rural del segle XVII», Revista de Catalunya, nueva etapa, Barcelona, 1987, 5, pp. 85-86.

6. Texto reproducido por BoronAT, P.: Los moriscos españoles..., I, pp. 628-629. 
de casarse muchos, que todas son causas poderosas para impedir la multipliçación y apocar la gente, al mismo paso van creciendo y multiplicando los moriscos.» ${ }^{7}$ Jaime Bleda añadía a estas causas el matrimonio universal morisco, que curiosamente ligaba a su pobreza, pensando quizás en las menguadas dotaciones que el morisco precisaba para casarse. El párroco de Corbera escribía que «multiplicantur enim nimirummodum propter parcitatem cibi, et potus, qua utuntur, et quia omnes vacant matrimoniis.» No voy a entrar en este tema, que requeriría una investigación minuciosa, pero esta imagen del matrimonio morisco concuerda estrechamente con el modelo matrimonial no europeo que definió en el siglo XX el demógrafo británico John Hajnal ${ }^{8}$.

Esta imagen negativa de la minoría morisca se mantuvo durante todo el siglo XVII y buena parte, si no todo, el XVIII, aunque se trata de un tema nada estudiado. La visión del «moro» como el enemigo, probablemente propiciada por la perpetuación de los ataques piráticos en la costa, aparece con nitidez en algunas obras dramáticas representadas con éxito en el Corral de las Comedias valenciano durante esta centuria ${ }^{9}$. Sin embargo, en algún momento indeterminado del siglo XIX, probablemente en los años treinta o cuarenta de esta centuria, la moriscofobia o morofobia tradicional dio paso a la moriscofilia, aunque no de forma universal, como veremos inmediatamente. El hecho debe tener relación con la difusión de la mentalidad romántica, pero se trata de un fenómeno más complejo que merecería un estudio detenido. Por un lado tenemos el testimonio de los viajeros extranjeros. Éstos nunca habían identificado, en siglos anteriores, a los valencianos, o de forma más general a los españoles, con los norteafricanos, y ahora lo hacen de forma habitual ${ }^{10}$. Pero también encontramos esta valoración entre autores valencianos. El año 1889, por ejemplo, Melchor Bellver y Vicente del Cacho publicaron en Castelló de la Plana un libro en el que destacaban la fuerte impronta árabe de la agricultura comercial valenciana, expresando por lo tanto una opinión que era exactamente la contraria de la de los contemporáneos de los moris$\cos ^{11}$. Incluso en la letra oficiosa del himno regional de la Comunidad Valenciana, obra de Maximiliano Tous del año 1909, se crea un entorno que reivindica implícitamente los orígenes musulmanes del País Valenciano, sin hacerse ninguna referencia a los pobladores catalanes o aragoneses.

7. Texto reproducido por BORONAT, P.: Los moriscos españoles..., I, p. 109.

8. HajnAl, John: «European Marriage Patterns in Perspective», en Glass, D. V., y Eversley, D. E. C. eds.: Population in History, Londres: Edward Arnold, 1974, pp. 101-143; y, del mismo autor, «Two Kinds of Pre-industrial Household Formation System», en WALl, R., RoBIN, J., y LASLETT, P., eds.: Family Forms in Historic Europe, Cambridge: CUP, 1987², pp. 65-104.

9. SuredA, François: Le theâtre dans la société valencienne du XVIIIe siècle, Perpignan: Presses Universitaires de Perpignan, 2004, pp. 455-461.

10. Ardit, M.: «Una mirada distant a les hortes valencianes», Afers, Catarroja, 2004, 47, pp. 29-43, esp. pp. 35-37.

11. BELlVER, Melchor, y CACHO, Vicente del: Influencia que ejerció la dominación de los árabes en la agricultura,industria y comercio de la provincia de Castellón de la Plana, Castelló de la Plana:Imprenta de F. Segarra, 1889. 
Esta misma percepción tuvieron algunos historiadores de los moriscos. El catalán Florencio Janer, por ejemplo, atribuía a los moriscos todos los progresos agrícolas y el monopolio de la comercialización de los productos agrarios. En términos muy parecidos se expresaba José Muñoz y Gaviria, quien escribía que «no fue tanto el mal que originó a España la pérdida de esta crecidísima parte de su población por su número como por la clase y la índole de la población espulsada, que era precisamente la de los agricultores, comerciantes e industriales, la población en fin más productora y la más contribuyente. El cultivo del azúcar, del algodón y de los cereales, la cría del gusano de seda en que tan aventajados eran los moriscos, quedó enteramente abandonada en las fértiles campiñas de Valencia, Murcia y Granada. Las fábricas de papel, de sedas, de paños que tenían en los castillos, tuvieron que cerrarse porque, no habituados los españoles a las artes y a la industria, miraban con desdén y desprecio el ejercicio de aquellas artes, que habian acaparado para sí y con gran provecho los moriscos. $\rangle^{12}$ En estos autores, la perspectiva arabista o africanista era la consecuencia de una convicción liberal que rechazaba la expulsión de los moriscos como una medida fruto de la intolerancia de una clase dirigente que despreciaba las actividades productivas. En parte pretendía ser una explicación de la decadencia española, aunque esta interpretación no aparece en los escritos de los arbitristas del siglo XVII ni en los proyectistas del XVIII.

Sin embargo los hagiógrafos del patriarca Ribera no podían compartir esta interpretación. Juan de Ribera, arzobispo de Valencia entre 1569 y 1611, y virrey entre 1602 y 1604, había sido un entusiasta partidario de la expulsión. Aunque había sido beatificado en 1796, a finales del XIX se tramitaba su canonización, que no fue proclamada hasta 1960. Los hagiógrafos del arzobispo, en este caso dos valencianos, Manuel Danvila y Pascual Boronat, no podían por lo tanto compartir la percepción de la minoría morisca como un elemento decisivo de la economía valenciana del siglo XVI. El primero de ellos, enfrentándose a la interpretación moriscófila, escribió que «no pudiendo condecorar a los moriscos con ningún signo de cultura, se ha ponderado lo que representaban como los brazos activos de la agricultura y de las artes en las comarcas donde habitaban. Es preciso padecer una oftalmía histórica recalcitrante para sostener tan vulgar despropósito»y en términos muy parecidos se expresó Boronat en diversos lugares de su extensa obra ${ }^{13}$. Puede pensarse que estos autores expresaban también otro tópico y probablemente es así, pero la calidad de su investigación era muy superior a la de sus opositores.

12. JANER, Florencio: Condición social de los moriscos de España, causas de su expulsión y consecuencias que ésta produjo en el orden económico y político, Madrid: Real Academia de la Historia, 1857, esp. pp. 47-48; MuÑOZ Y GAVIRIA, José: Historia del alzamiento de los moriscos, su expulsión de España y sus consecuencias en todas las provincias del reino, Madrid: Mellado, 1861, pp. 186-187.

13. DanVIla y Collado, Manuel: La expulsión de los moriscos españoles. Conferencias pronunciadas en el Ateneo de Madrid, Madrid: Fernando Fe, 1889, pp. 335-336. 


\section{PERSPECTIVAS HISTORIOGRÁFICAS ACTUALES}

Los historiadores del siglo XX han oscilado entre las dos tendencias que he denominado moriscófoba y moriscófila, aunque por razones diferentes, o al menos básicamente diferentes de las señaladas hasta ahora. Desde 1901, fecha de publicación de Los moriscos españoles de Pascual Boronat, el primer estudio serio sobre los moriscos valencianos y su expulsión fue el del historiador argentino Tulio Halperín Donghi, cuya primera parte se publicó en $1955^{14}$. La obra fue el resultado de la tesis doctoral del autor, realizada durante una estancia en la École des Hautes Études en París y recogida de materiales en España, fundamentalmente en el Archivo General de Simancas y el Archivo del Reino de Valencia. Podemos partir de la suposición de que, por el hecho de ser argentino, Halperín Donghi no trabajó tan condicionado por prejuicios como los historiadores españoles. La imagen que da de la comunidad morisca está más cerca de la que tenían los contemporáneos del siglo XVI. Es imposible resumir en pocas palabras una obra tan rica de contenido como la del historiador argentino, pero la siguiente cita, en la que describe el territorio morisco, es bastante indicativa: «Esta tierra superpoblada de los granos pobres, de las majadas aldeanas, del trigo y del aceite, del algarrobo, es la tierra morisca por excelencia, la 'montaña' de que se hablaba en el siglo XVI, es decir, no necesariamente la zona alta, sino la espesura, la tierra no regada, de pobres cultivos perdidos en el matorral espinoso.» ${ }^{15} \mathrm{El}$ siguiente historiador que se aproximó al tema fue el francés Henri Lapeyre, cuya obra es de 1959. Aunque el estudio de Lapeyre analiza fundamentalmente la expulsión, también expresa una percepción de la sociedad y de la economía morisca muy próxima a la de Halperín. «Si nous reprenons - escribe - la distinction traditionnelle des terres de secano et de regadío, nous constatons que les morisques prédominaient dans les premières, à l'exception de la province actuelle de Castellon, où les hautes terres de Morella et du Maestrazgo formaient un solide bloc chrétien. (...) Voilà qui nous conduit à une constatation fondamentale de nature à surprendre ceux qui croyaient, sur la foi d'affirmations souvent répetées, que les fértiles huertas étaient le domaine de prédilection des morisques.» ${ }^{16}$ Joan Reglà, que publicó una interesante obra sobre el tema el año $1964^{17}$, no trató esta problemática, que cambiaría de rumbo poco después, el año 1977, con la publicación de la obra de Eugenio Ciscar, como veremos inmediatamente. Pero aunque la obra de Ciscar, de signo moriscófilo, ejerció una gran influencia, algunos historiadores posteriores siguieron manteniendo la perspectiva moriscófoba, como el historiador valenciano de la medicina Luis García Ballester. Escribía éste en 1984 que «los moriscos se asenta-

14. HALPERÍN DONGHI, Tulio: «Un conflicto nacional: moriscos y cristianos viejos en Valencia», Cuadernos de Historia de España, Buenos Aires, 1955, XXIII-XXIV, pp. 5-115, y 1957, XXV-XXVI, pp. 83-250. Este largo artículo se publicó en forma de libro, con el mismo título, en Valencia: Ediciones Alfonso el Magnánimo, 1980, obra que ha sido reeditada en 2008 por la Universidad de Valencia.

15. HALPERIN, T.: Un conflicto nacional... (edición de 1980), p. 68.

16. LAPEYre, Henri: Géographie de l'Espagne morisque, París: SEVPEN, 1959, pp. 25-26. Hay traducción castellana, Geografía de la España morisca, Valencia: Ediciones Alfonso el Magnánimo, 1986.

17. REGLÀ, Joan: Estudios sobre los moriscos, Valencia: Universidad de Valencia, 1964. 
ban, sobre todo, en los territorios de secano dedicándose, tanto en dominios de señorío como de realengo, a labores agrícolas o ganaderas de pastoreo, aunque también existiese una minoría - quizá la más pudiente-dedicada a labores de tipo mercantil y transporte de mercancías. Todos, incluso la pequeñisima minoría de moriscos ricos, vivían muy vinculados a la tierra y, en general, la pobreza y la dependencia respecto de los cristianos viejos -fueran éstos nobles o no- era su norma de vida.» ${ }^{18}$

La obra de Eugenio Ciscar a la que me he referido más arriba se tiene que explicar en función del ambiente intelectual predominante en la historiografía valenciana de los años setenta del siglo XX. Por un lado preocupaba mucho en aquel momento la debilidad industrial valenciana en el siglo XIX y buena parte del XX. Aunque el profesor Emili Giralt había propuesto el año 1968 una explicación multifuncional del fracaso relativo de la industrialización valenciana ${ }^{19}$, otros historiadores prefirieron una interpretación del fenómeno más estructural. Concretamente Mario García Bonafé explicó no sólo la fracasada industrialización sino también un supuesto atraso económico valenciano por el predominio de un régimen señorial opresivo que tenía precisamente su origen en la repoblación posterior a la expulsión de los moriscos el año $1609^{20}$. Al mismo tiempo, aunque su recepción llegó con cierto retraso, había mucha preocupación por la problemática de la transición del feudalismo al capitalismo, alentada por el debate DobbSweezy y su derivación, más actual en aquel momento, de la discusión sobre la crisis general del siglo XVII, es decir, por qué después de un siglo XVI que parecía anunciar el establecimiento de una estructura capitalista madura, la siguiente centuria no respondió a estas expectativas. Creo que todo ello explica el giro moriscófilo de Eugenio Ciscar, quien consideró que la expulsión de los moriscos estuvo en la base de una fractura en el proceso de transición del feudalismo al capitalismo en el País Valenciano. Este autor afirmaba, en la conclusión de su obra, que «nos parece evidente que las motivaciones económicas y la protección de los intereses nobiliarios estuvieron presentes, junto con la conciencia de la resistencia morisca a la cristianización y de sus dimensiones políticas, en la gestación del decreto de expulsión. Su ejecución y la nueva situación creada con la repoblación supondrá una refeudalización, una extensión e intensificación de las relaciones feudales, traducida en la disminución del jornalero, incipiente proletariado rural, desaparición de la propiedad alodial, aumento de la enfiteusis, mayor control y superiores exigencias señoriales, así como una ruptura de las anteriores estructuras comerciales y descenso de las actividades artesanales. Igualmente, se cer-

18. GARCÍA BALLESTER, Luis: Los moriscos y la medicina. Un capitulo de la medicina y la ciencia marginadas en la España del siglo XVI, Barcelona: Labor, 1984, p. 13.

19. Giralt I RAVENTós, Emili: «Problemas históricos de la industrialización valenciana», Estudios Geográficos, Madrid, 1968, 112-113, pp. 369-394.

20. GARCÍA BONAFÉ, Mario: «El marco histórico de la industrialización valenciana», Información Comercial Española, Madrid, 1974, 485, pp. 135-146. 
cena el número y riqueza de una clase burguesa o para-burguesa, cristiana y morisca, y se limita su ulterior desarrollo.» ${ }^{21}$

La hipótesis de la refeudalización, divulgada a mayor escala por Ruggiero Romano en aquel momento, ya fue criticada poco después de publicado el libro de Ciscar por Mariano Peset $^{22}$, y yo mismo también lo he hecho en diferentes publicaciones ${ }^{23}$. El mismo Ciscar ha modificado su posición y en publicaciones posteriores ya no se expresa con la misma contundencia como lo hacía en 1977, aunque continúa pensando que la comunidad morisca valenciana era rica y dinámica, con las excepciones lógicas de una sociedad en proceso de diferenciación interna, y no era básicamente diferente de la cristiana $^{24}$. De algún modo la discusión más estructural y teórica anterior ha quedado transformada en otra que lo que intenta averiguar es si había o no un sector de moris$\cos$ ricos. Ciscar utiliza una estrategia enumerativa y ciertamente los testimonios que presenta son numerosos. Sin embargo sigo pensando que una cuestión macrohistórica como ésta se ha de resolver en términos macrohistóricos y no mediante una enumeración de moriscos acomodados ${ }^{25}$.

La discusión de este asunto es y debe ser puramente académica, y así la planteo y la he planteado siempre. En ciencias sociales deben dejarse siempre a un lado los juicios de valor, las filias y las fobias, aunque quizás esto no siempre se consigue. Lo que me ha preocupado siempre, y me sigue preocupando, es si la expulsión de los moriscos fue o no un obstáculo en el proceso de desarrollo capitalista del País Valenciano. Desde que publiqué mi primer artículo sobre el tema en 1987 pienso, y sigo pensando, que la expulsión no sólo no significó esto, sino que hay indicios que señalan que pudo ser todo lo contrario. Adopto en este sentido la interpretación de los contemporáneos, aunque reconozco que pudo estar equivocada y plagada de prejuicios. Por esta razón he planteado en varias ocasiones la cuestión utilizando indicadores macrohistóricos, en los que es más difícil introducir una interpretación sesgada.

21. Ciscar Pallarés, Eugenio: Tierra y señorio en el País Valenciano (1570-1620), Valencia: Del Cenia al Segura, 1977, p. 325.

22. PeSET ReIG, Mariano: Dos ensayos sobre la historia de la propiedad de la tierra, Madrid: Revista de Derecho Privado, 1982, p. 197.

23. ARdiT LuCAS, Manuel: «Expulsió dels moriscos i creixement agrari al País Valencià», Afers, 5-6, 1987, pp. 273-316; «Els moriscos valencians. Una reflexió (parcialment) alternativa», en L'expulsió dels moriscos. Conseqüències en el món islàmic $i$ en el món cristià, Barcelona: Generalitat de Catalunya, 1994, pp. 72-85.

24. Ciscar Pallarés, Eugenio: Moriscos, nobles y repobladores, Valencia: Ediciones Alfonso el Magnánimo, 1993.

25. Juan Francisco Pardo Molero ha publicado recientemente una síntesis desapasionada de la cuestión y ha remarcado con acierto el contraste entre la aproximación local a la problemática que tratamos, hecha por Ciscar, y la global que propongo, aunque parece inclinarse por aquel autor, deslumbrado por su estudio sobre la Valldigna, en mi opinión todavía más local. Ver PARDO MOLERO, Juan Francisco: «Los moriscos valencianos. Vigencia de un tópico historiográfico», Revista de Historia Medieval, Valencia, 12, 20012002, pp. 155-184; y CISCAR PALLARÉs, Eugenio: La Valldigna, siglos XVI y XVII. Cambio y continuidad en el campo valenciano, Valencia: Diputación de Valencia, 1995. 
La cuestión que habría que plantear es cómo habría evolucionado la economía valenciana si los moriscos no hubieran sido expulsados, es decir, formular aquello que los llamados nuevos (ahora ya no tan nuevos) historiadores de la economía llaman una hipótesis contrafactual. La calidad de la información disponible no permite aplicar modelos econométricos, pero sí que se pueden examinar todo un conjunto de indicadores macroeconómicos y ver cómo evolucionaron después de la expulsión. En ocasiones se pueden diferenciar territorios moriscos y cristianos viejos, aunque la diferenciación no siempre se puede hacer de forma nítida. La idea de esta estrategia deriva de una sugerencia de Earl J. Hamilton, quien observó que la evolución de los precios valencianos en los años posteriores al extrañamiento de los moriscos fue exactamente la contraria de que habría sido esperable. Efectivamente, después de la expulsión de la supuestamente dinámica población morisca se debería haber experimentado un notable descenso de la oferta de alimentos y, por lo tanto, un aumento de los precios. En cambio, según el historiador norteamericano, «los precios agrícolas en los dos años siguientes a la gran expulsión de 1609, año en el que salió la gran masa de moriscos, no subieron más rápidamente que los no agrícolas en 1612-1615, y marcharon muy por detrás de la serie no agrícola en el segundo cuarto del siglo XVII. Es indudable que la expulsión no arruinó la agricultura.» ${ }^{26}$

Lo mismo sucede, como veremos, con los diezmos, que Hamilton no estudió. Ni los diezmos ni los precios presentan alteraciones que hagan suponer que ocurrió tal catástrofe. Concretamente los diezmos valencianos se parecen mucho a cualquier otra serie española, incluso de territorios sin moriscos. Un hipotético historiador del futuro que, tras la desaparición de toda la documentación disponible por cualquier eventualidad que podamos imaginar, tan sólo dispusiera para estudiar el siglo XVII valenciano de la serie de precios y de diezmos, no intuiría ningún acontecimiento de envergadura a comienzos del Seiscientos. Con estos indicadores la expulsión de los moriscos se convierte en un suceso invisible. O las series de precios y de diezmos no sirven para nada, o este hecho debería inclinar a una cierta preocupación, cosa que pocos historiadores han hecho. Intentaré desarrollar en las páginas que siguen algunas sugerencias que nos permitan explicar esta invisibilidad de la expulsión de los moriscos en los indicadores a los que he hecho referencia. Para ello examinaré la evolución de la población y su distribución geográfica, la de la producción agraria y finalmente la estructura de la propiedad de la tierra en algunas localidades investigadas antes y después de la expulsión.

\section{CAMBIOS EN LA ESTRUCTURA DEL POBLAMIENTO DESPUÉS DE LA EXPULSIÓN}

El planteamiento de este ejercicio proviene de una sugerencia de Tulio Halperín Donghi. Escribe este autor: «Mientras tanto la repoblación avanza. No sin altibajos. Si oímos a los que presenciaron esa gigantesca operación nos dirán que fue a la vez

26. Hamilton, Earl J.: El florecimiento del capitalismo. Ensayos de historia económica, Madrid: Alianza Editorial, $1984^{2}$, p. 129. 
un gigantesco fracaso. En parte lo fue, sin duda; las cicatrices de la gran mutilación no se borraron tan fácilmente; ya Fonseca, en 1610, observaba que en el periodo, aunque breve, desde que las tierras quedaban vacías, se estaban produciendo daños irreparables; cada día que pasaba el patrimonio dejado por los moriscos se amenguaba. Pero era un fracaso sobre todo desde el punto de vista de los observadores que se habían formado una idea algo simplista de lo que iba a ser la repoblación: para ellos se trataba de poner una casa de cristianos viejos alli donde había habido antes una casa morisca. Y eso, desde luego, no iba a ser posible. La distribución de la población en la Valencia cristiano-morisca estaba directamente vinculada a la división de esa Valencia en dos grupos nacionales que eran a la vez grupos sociales: no dependía tan sólo de la capacidad de la tierra para sostener a grupos humanos más o menos densos. Esa distribución era ya inalcanzable luego de la expulsión; lo que puede preguntarse y no se preguntaban quienes, por ejemplo, se lamentaban de que los 1.200 moriscos de la Vall de Guadalest hubiesen sido reemplazados por sólo 120 cristianos viejos, es si la restauración de esa forma de distribución demográfica era deseable o ventajosa. $\rangle^{27}$

He diseñado el experimento de la siguiente forma. He distribuido la población del País Valenciano en tres momentos cronológicos: el año de la expulsión, 1609, utilizando el llamado vecindario de Caracena, y los dos censos completos posteriores, el vecindario de Campoflorido de 1713 y el censo de Floridablanca de 1787 . He agregado las cifras de población en nueve unidades territoriales o macrocomarcas para hacer el análisis más sencillo y, dentro de cada una, he distinguido entre localidades moriscas -exmoriscas después de 1609- y de cristianos viejos. He calculado para cada una el porcentaje de la población respecto del total. Como los cálculos han sido internos para cada recuento no se ha hecho ninguna conversión de vecinos a habitantes, ni tampoco ninguna corrección de las cifras. Los recuentos de 1609 y de 1713 proporcionan cifras de vecinos y el censo de 1787 de habitantes; además el vecindario de 1713 es muy defectivo. Esto implica que las cifras absolutas de este último recuento son incorrectas, pero no las proporciones, si suponemos, como es probable, que los errores se distribuyen de forma aleatoria. El resultado se muestra en la Tabla 1. Omito los detalles de fuentes y otras consideraciones y me remito a la publicación en la que se presentaron originalmente ${ }^{28}$.

Como se desprende de una lectura atenta de la tabla, todas las áreas moriscas perdieron población relativa después de la expulsión y sólo una, las Llanuras Centrales, donde la población era pequeña, tardó en hacerlo hasta 1787. En el País Valenciano en su conjunto la población del territorio morisco, que representaba un tercio de la población en 1609 (exactamente un 32,35 por 100), pasó a ser de una cuarta parte, con una diferencia muy pequeña entre 1713 y 1787 . El hecho de que los resultados de un censo muy deficiente, como el de 1713, y uno de gran calidad, como el de Floridablanca de 1787, sean tan parecidos, corrobora la asunción hecha antes de que los errores del

27. HALPERÍN, T.: Un conflicto nacional..., p. 267.

28. ARDIT, M.: «Expulsió dels moriscos i creixement agrari...», esp. pp. 283-287. 
censo de 1713 se distribuyen de forma aleatoria. Además revela que esta nueva estructura del poblamiento fue estructural. La hipótesis de Halperín de que el proceso de repoblación fue mucho más que eso, ya que implicó un cambio radical de modelo demográfico espacial, parece quedar corroborada.

Tabla 1

Cambios en la distribución espacial de la población valenciana (1609-1787)

\begin{tabular}{|l|c|c|c|c|c|c|}
\hline \multirow{2}{*}{} & \multicolumn{2}{|c|}{1609 (vecinos) } & \multicolumn{2}{c|}{1713 (vecinos) } & \multicolumn{2}{c|}{1787 (habitantes) } \\
\cline { 2 - 7 } & $\begin{array}{c}\text { Localidades } \\
\text { moriscas }\end{array}$ & $\begin{array}{c}\text { Localidades } \\
\text { cristianas }\end{array}$ & $\begin{array}{c}\text { Localidades } \\
\text { moriscas }\end{array}$ & $\begin{array}{c}\text { Localidades } \\
\text { cristianas }\end{array}$ & $\begin{array}{c}\text { Localidades } \\
\text { moriscas }\end{array}$ & $\begin{array}{c}\text { Localidades } \\
\text { cristianas }\end{array}$ \\
\hline Llanuras meridionales & $33,62 \%$ & $66,38 \%$ & $27,13 \%$ & $72,87 \%$ & $27,20 \%$ & $72,80 \%$ \\
\hline $\begin{array}{l}\text { Montañas } \\
\text { meridionales }\end{array}$ & $34,18 \%$ & $65,82 \%$ & $22,08 \%$ & $77,92 \%$ & $24,21 \%$ & $75,79 \%$ \\
\hline Marinas & $62,29 \%$ & $37,71 \%$ & $49,42 \%$ & $50,58 \%$ & $44,81 \%$ & $55,19 \%$ \\
\hline Huertas & $45,56 \%$ & $54,44 \%$ & $34,43 \%$ & $65,57 \%$ & $32,91 \%$ & $67,09 \%$ \\
\hline Llanuras Centrales & $12,32 \%$ & $87,68 \%$ & $12,62 \%$ & $87,28 \%$ & $9,57 \%$ & $90,43 \%$ \\
\hline $\begin{array}{l}\text { Llanuras } \\
\text { septentrionales }\end{array}$ & $16,26 \%$ & $83,74 \%$ & $12,05 \%$ & $87,95 \%$ & $14,45 \%$ & $85,55 \%$ \\
\hline Tierras Altas & - & $100 \%$ & - & $100 \%$ & - & $100 \%$ \\
\hline Mont. Septentrionales & $39,66 \%$ & $60,34 \%$ & $24,83 \%$ & $75,17 \%$ & $27,77 \%$ & $72,23 \%$ \\
\hline Montañas centrales & $78,60 \%$ & $21,40 \%$ & $71,77 \%$ & $28,23 \%$ & $73,32 \%$ & $26,68 \%$ \\
\hline Total & $32,35 \%$ & $67,65 \%$ & $23,98 \%$ & $76,02 \%$ & $24,97 \%$ & $75,03 \%$ \\
\hline
\end{tabular}

Una lectura desagregada muestra, sin embargo, matices importantes. En algunas macrocomarcas el descenso de la población relativa de las áreas moriscas fue pequeño, aunque la interpretación probablemente no es siempre la misma. El pequeño descenso que muestran las Llanuras meridionales parece indicar que en esta área los moriscos no estaban arrinconados en territorios especialmente desfavorecidos. Probablemente encontraríamos resultados parecidos en zonas más pequeñas si hubiésemos hecho el análisis de forma más desagregada. Se trata de las áreas donde se encuentran en abundancia elites moriscas. El caso de las Montañas Centrales, donde el descenso relativo de la población fue también pequeño, es probablemente distinto, ya que aquí ejerce una influencia considerable el hecho de que la única localidad cristiana de la Foia de Bunyol fuese la deprimida Siete Aguas.

Todas las otras regiones experimentaron descensos superiores a la media del País Valenciano, sobre todo aquellas zonas en las que los moriscos ocupaban los estrechos valles montañosos, como las Marinas, donde el descenso es del 17 por 100, y las Montañas Septentrionales, donde es del 12 por 100. Pero resulta sorprendente que sigamos encontrando fuertes descensos en las zonas tópicas de la prosperidad morisca, como las Huertas (12 por 100). Si desagregamos esta última macrocomarca, seguimos encontrando fuertes bajadas en la Safor (17 por 100) y la Ribera Alta (12 por 100), siendo sólo menores en las prósperas comarcas de la Costera y la Ribera Baixa, donde la población morisca era pequeña. 
Concluiré de nuevo este apartado con un párrafo de Halperín Donghi: «Casi dos siglos después de la expulsión, en sus andanzas por tierras de Valencia, en el alto Espadán y en otros rincones montañosos, Cavanilles encontró lugares abandonados, aldeas de las que sólo sobrevivía el recuerdo, vivo testimonio de las ruinas y las desolaciones provocadas por el alejamiento de los moriscos. Pero esas heridas que en los rincones de la montaña permanecían abiertas aún dos siglos después de la expulsión (y siguen estándolo aún hoy: en esta Valencia actual, de población fabulosamente densa, más de una aldea que fue morisca tiene menos habitantes que en 1609), esas heridas en otras comarcas cicatrizaron en pocos años. Han terminado, en cambio, ya para siempre, esos pululantes recovecos de la montaña donde se agolpaba una población que no encontraba salida.» ${ }^{29}$

\section{LA EVOLUCIÓN DE LA PRODUCCIÓN AGRARIA}

Para estudiar la evolución de la producción agraria de forma agregada es preciso recurrir a la fuente clásica para este tipo de investigaciones en la época preestadística: el diezmo eclesiástico. El antiguo reino de Valencia estaba dividido, con la excepción puntual de dos localidades que pertenecían al arzobispado de Zaragoza (Bechí y Olocau del Rey) entre cuatro obispados: los de Orihuela, Valencia, Segorbe y Tortosa. De todos ellos he estudiado los diezmos del arzobispado de Valencia, que se extendía por gran parte del territorio, de modo que podemos considerar estos datos suficientemente representativos.

La sede valenciana recaudaba diferentes tipos de diezmos, de los cuales el más importante era el llamado de pa $i$ vi, o diezmo mayor, que gravaba principalmente los granos y el vino, aunque en muchas ocasiones también se integraban en él todas las demás producciones agrícolas. Sólo en algunos territorios muy limitados existían otros tipos de diezmo, como el de paner, que gravaba productos hortícolas, y el de fulla, que gravaba la hoja de morera, aunque generalmente se pagaba en metálico según acuerdos suscritos con el arzobispado. Los diezmos de carnatge o ganado y el de peix no se han utilizado en esta investigación.

Los diezmos del arzobispado de Valencia se arrendaban en pública subasta por un período de tres o cuatro años. Esta circunstancia plantea numerosas limitaciones. La cuantía del diezmo refleja las expectativas de producción y no la producción agraria real en el período de vigencia del arriendo. Por esta razón los diezmos muestran un pequeño retardo, de tres o cuatro años, respecto a la producción real. Probablemente las limitaciones son más que ésta a la que acabo de aludir. Existen razones poderosas que hacen suponer que el diezmo arrendado estaba muy influido por otro cúmulo de circunstancias económicas, como la propia oferta y demanda en el mercado financiero, la liquidez monetaria, los cambios de cultivos y otros. Se trata de una problemática bastante compleja que pretendo estudiar en otro trabajo y que ahora necesariamente hay que dejar aparcada.

29. HALPERÍN, T.: Un conflicto nacional..., p. 275. 
Sea lo que sea se trata de la única fuente disponible y hay que aceptarla con todas sus limitaciones. En todo caso a efectos comparativos todas las series presentan los mismos problemas, igual que ocurría con los datos de población. El arzobispado de Valencia tenía dividido su territorio en un conjunto de distritos decimales llamados delmaris. A lo largo de la Edad Moderna, pero sobre todo en el siglo XVIII, estos delmaris fueron subdividiéndose en territorios más pequeños llamados filloles. Éstos se han integrado en el delmari original para que la serie resultante corresponda siempre al mismo territorio. Siguiendo la metodología habitual en este tipo de estudios, las series originales se han deflactado con los precios del trigo de la ciudad de Valencia, con la información aportada por Earl J. Hamilton, José-Miguel Palop y estudios míos para finales del siglo XVIII y comienzos del XIX. Con el producto decimal deflactado se han elaborado series de números índice sobre el período base 1585-1599, bastante estable y anterior a la expulsión de los moriscos. Las series agregadas son la media aritmética de las series individuales. Los territorios de las agregaciones a veces coinciden con los utilizados en el análisis de la población y a veces no, ya que en ocasiones he procedido a una mayor desagregación. Concretamente he separado las comarcas de la Safor y la Costera de la macrocomarca de las Huertas. Siempre que ha sido posible se han separado los delmaris cristianos de los moriscos. Los resultados, cuyo detalle puede verse en la publicación a la que ya he hecho repetidas referencias ${ }^{30}$, no son tan nítidos como en el caso de la población y precisan de unos comentarios matizados, que probablemente no sean muy exactos e incluso en algunos casos incorrectos. Se trata de un tema abierto que precisaría de muchas más investigaciones locales para quedar mejor establecido. El comentario quizás más evidente es el que se desprende de la evolución del diezmo en todo el territorio del arzobispado de Valencia, representado en la Gráfica 1.

Como he señalado en páginas anteriores, la expulsión de los moriscos es invisible en la gráfica. Ciertamente se produce una caída del diezmo, bastante brusca, en los años posteriores a 1609 , pero es mucho menor que la que se produjo a comienzos del siglo XVIII como consecuencia de la guerra de Sucesión, que otras crisis bien visibles en los años 40, 50 y 60 de esta centuria y, sobre todo, muy inferior a la formidable caída provocada, a comienzos del siglo XIX, por la guerra de la Independencia. Un historiador hipotético que sólo dispusiera de esta información no podría afirmar que el País Valenciano, en la medida que está representado por el arzobispado de Valencia, experimentara una crisis social y económica grave a comienzos del siglo XVII. Como mucho podría apreciar la existencia de un ciclo entre los años 80 del siglo XVI y el primer decenio del XVII. Es cierto que los diezmos siguen bajando durante la primera mitad del siglo XVII, pero el punto más bajo, con un nivel similar al alcanzado por los diezmos a mediados del siglo XVI, se alcanza en los años 40 del Seiscientos, casi medio siglo después de la expulsión de los moriscos. Si comparamos la serie valenciana con otras españolas, incluso de territorios sin población morisca -cosa que pretendo hacer en otro trabajo- encontramos grandes similitudes. El descenso continuado del diezmo

30. ARDIT, M.: «Expulsió dels moriscos i creixement agrari...», pp. 292-294. 
Gráfica 1. Evolución del diezmo mayor Índices. Base: 1585-1599=100. Arzobispado de Valencia

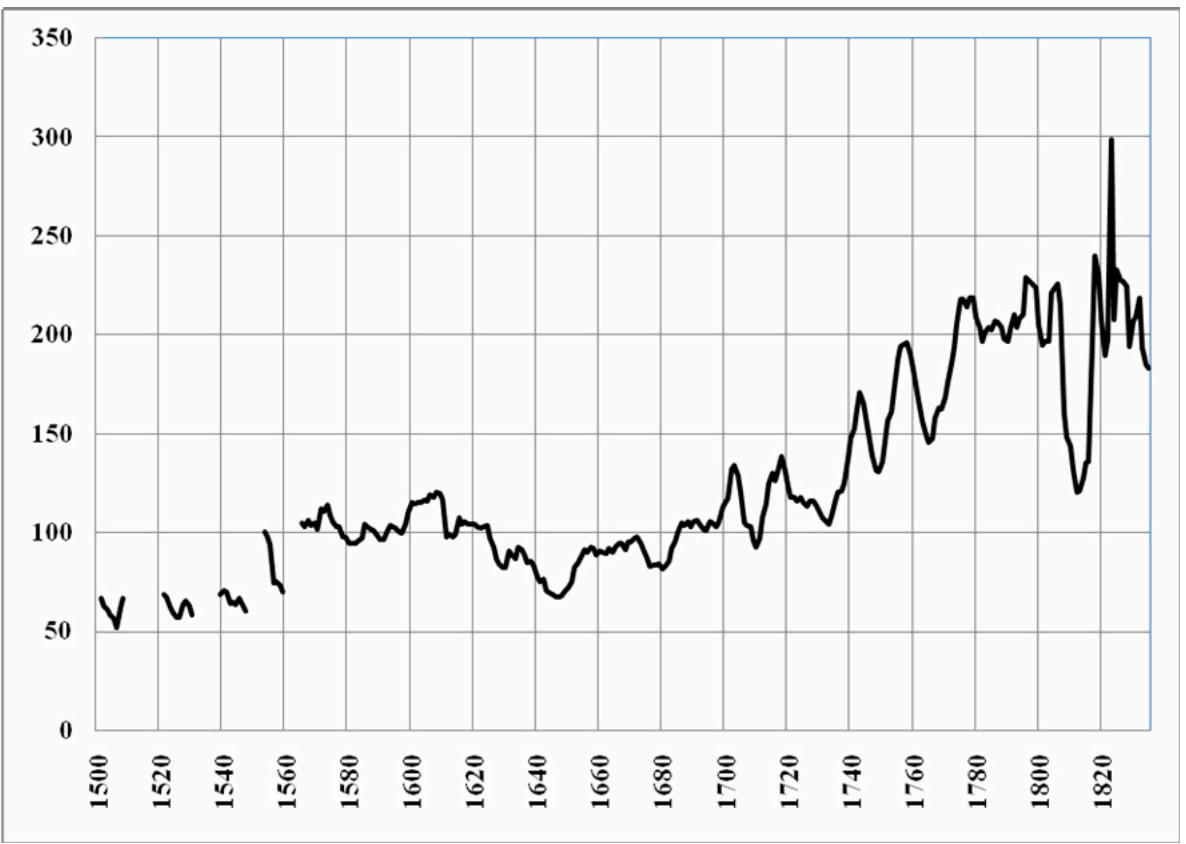

Gráfica 2. Evolución del diezmo mayor Índices. Base: 1585-1599=100. Montañas meridionales

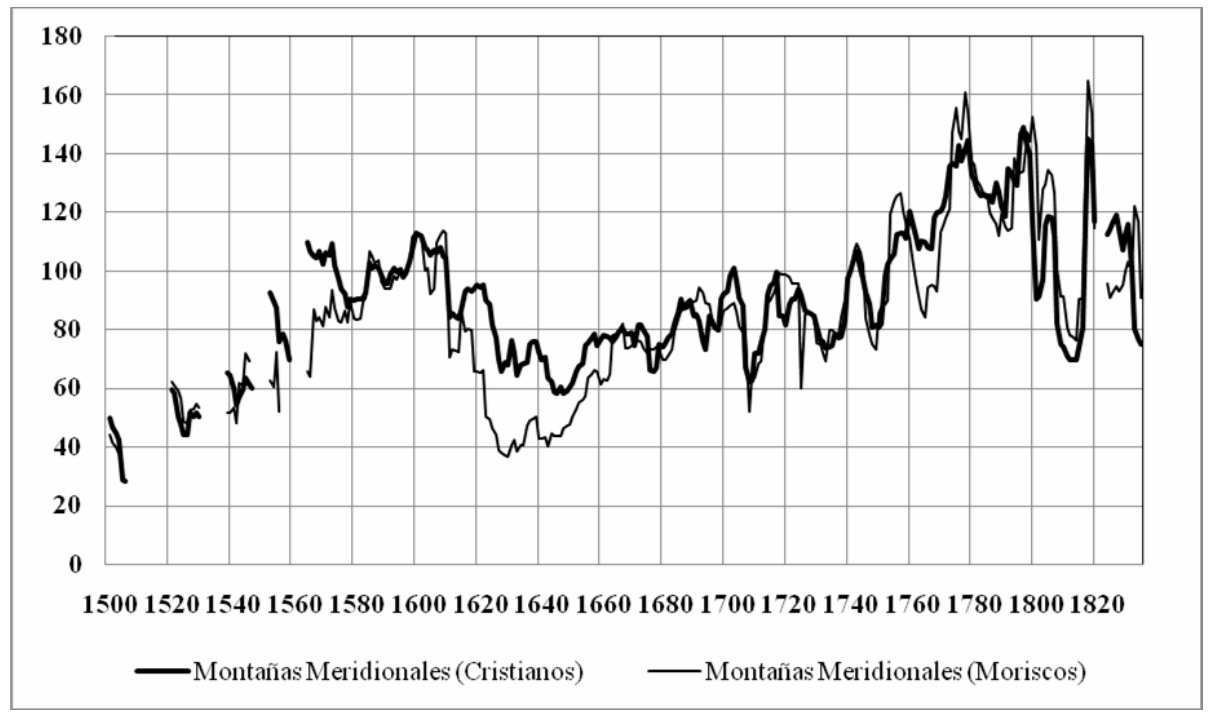


en la primera mitad del Seiscientos parece responder más a la compleja crisis del siglo XVII que a la expulsión de la población islámica valenciana.

El análisis por macrocomarcas o comarcas permite añadir algunas matizaciones. En las Montañas meridionales, que incluye las comarcas del Comtat, l'Alcoià y la Vall d'Albaida (Gráfica 2), la caída posterior a la expulsión de los moriscos fue muy visible (al contrario que en la gráfica general), sobre todo en las localidades moriscas. A partir de 1670 aproximadamente ambas series se igualan y las localidades moriscas alcanzan un nivel de producción similar al de las cristianas, con un descenso relativo de su población de un 10 por 100 .

La evolución de las Marinas fue muy parecida, aunque no exactamente igual. Aquí también se iguala el nivel productivo de las áreas moriscas y cristianas a partir de 1670 , aunque en este caso con un descenso relativo de la población del antiguo territorio morisco del 17 por 100. Una población pues, notoriamente inferior, logró alcanzar el mismo nivel de producción, lo parece indicar una mayor eficiencia de la agricultura cristiana.

En las comarcas de la Safor y de la Costera, de agricultura muy dinámica, no se han podido separar los diezmarios cristianos y los moriscos. La crisis posterior a la expulsión fue mayor en la Safor que en la Costera, lo que parece indicar dificultades en la repoblación y recuperación del cultivo, probablemente sobre todo de la caña de azúcar. Como en los casos anteriores ambas series se igualan en los años 70 del siglo XVII.

La macrocomarca de las Riberas (Ribera Alta y Ribera Baixa) experimentó un crecimiento agrario notable en el período, probablemente debido a la extensión del cultivo del arroz y de la morera. En este territorio, al contrario que en los examinados anteriormente, el territorio morisco no logró nunca alcanzar al cristiano. Aquí me parece evidente la explicación, ya que los moriscos habitaban las peores tierras. Territorios como el marquesado de Llombai o la baronía de Sumacàrcer difícilmente podían alcanzar los niveles de las fértiles huertas de Alzira, Algemesí o Carcaixent.

La evolución de las áreas moriscas y cristianas de las Huertas (agregación de la comarca de l'Horta i la del Camp de Morvedre) fue exactamente la contraria. Aquí las localidades cristianas no muestran más que un ligerísimo descenso después de 1609, pero en el siglo XVIII, sobre todo después de 1640, el territorio morisco superó amplísimamente al cristiano. Sólo se me ocurre una explicación. La comarca de l'Horta era sin duda la más rica del País Valenciano y debía haber alcanzado a mediados del siglo XVIII un nivel productivo difícilmente superable por una agricultura tradicional. En cambio las tierras marginales moriscas de este conjunto territorial tenían aún posibilidades de expansión mediante las roturaciones, crecimiento que consiguieron con una población relativa inferior en un 12 por 100 a la que tenían en 1609.

En las Llanuras Centrales, macrocomarca en la que se integran el Camp de Túria y la Foia de Bunyol, volvemos a ver, como en el caso de las Riberas, un superior crecimiento del territorio cristiano respecto del morisco después de la expulsión de forma constante.

En las Montañas Septentrionales y las Montañas Centrales no se han podido desagregar los diezmarios cristianos y los moriscos, pero la población morisca era mayo- 
Gráfica 3. Evolución del diezmo mayor Índices. Base: 1585-1599=100. Marinas

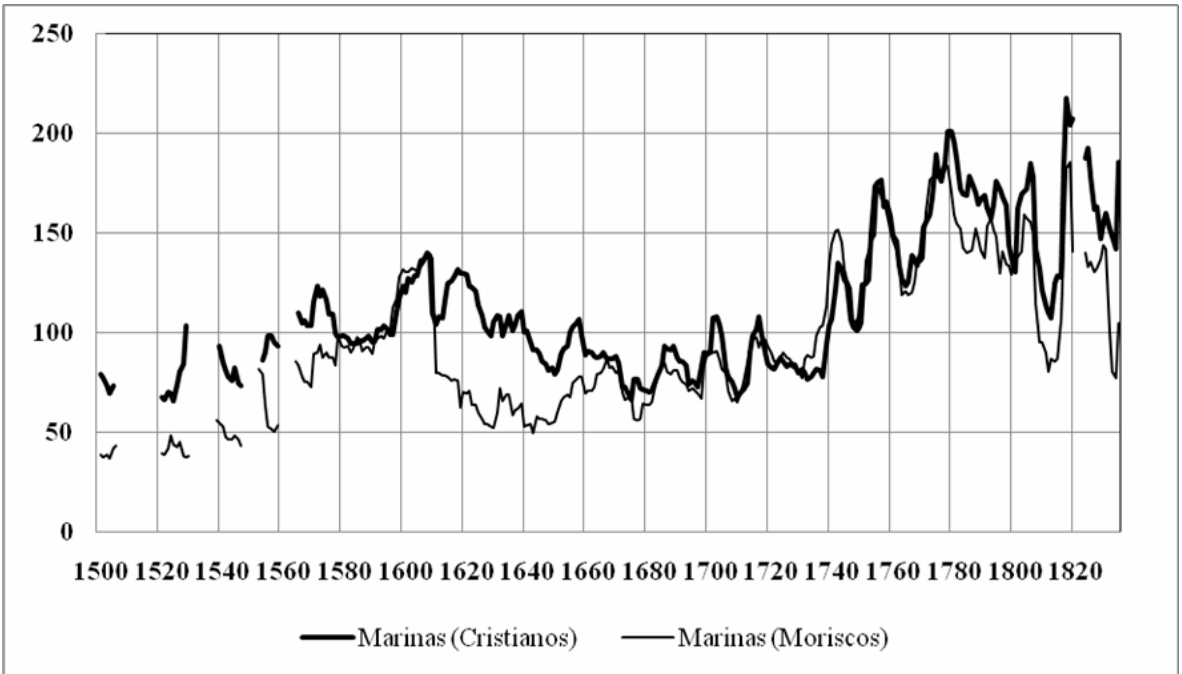

Gráfica 4. Evolución del diezmo mayor Índices. Base: 1585-1599=100. La Safor y la Costera

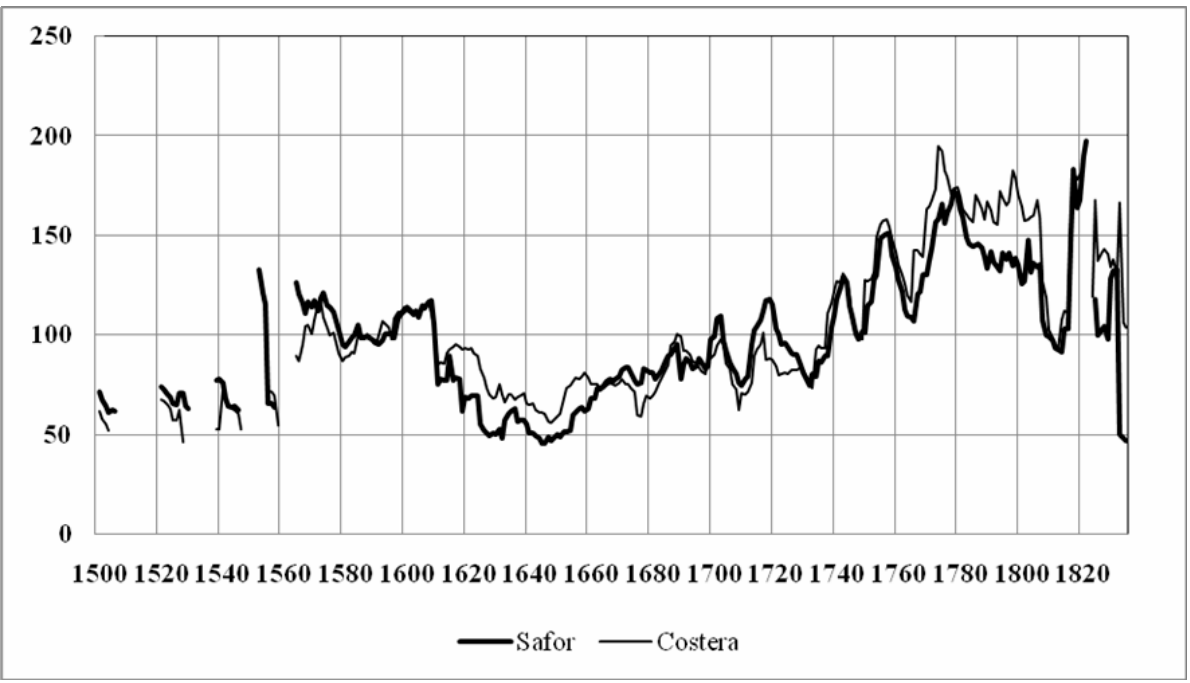


Gráfica 5. Evolución del diezmo mayor Índices. Base: 1585-1599=100. Riberas

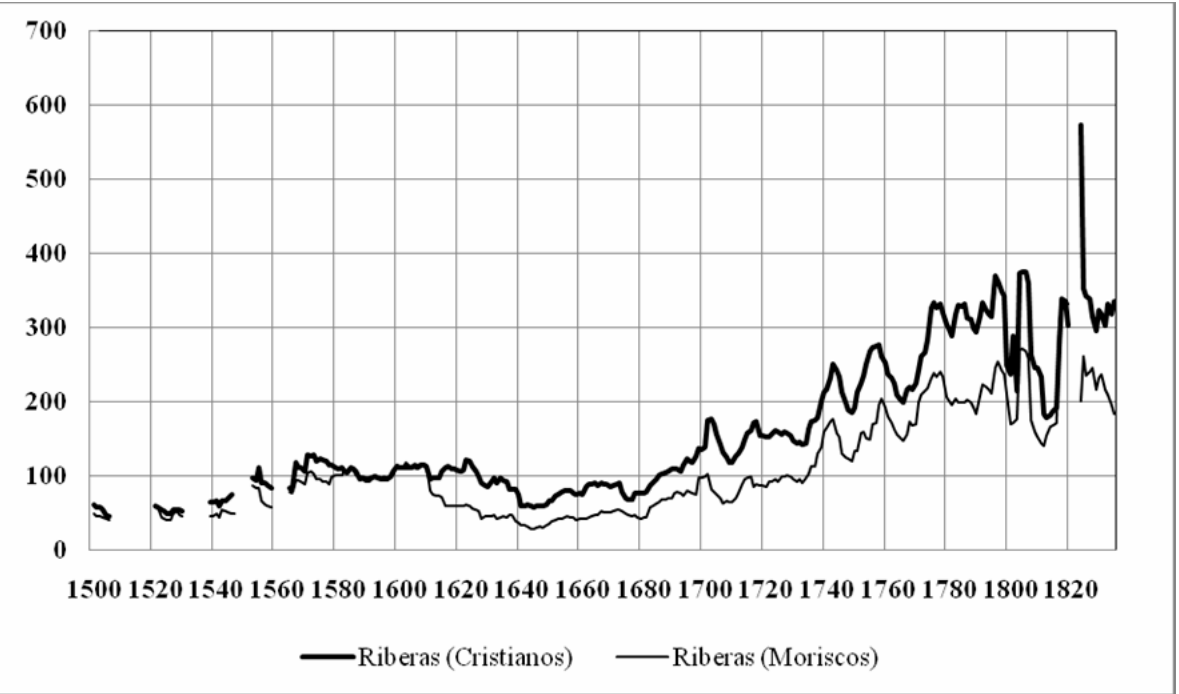

Gráfica 6. Evolución del diezmo mayor Índices. Base: 1585-1599=100. Huertas

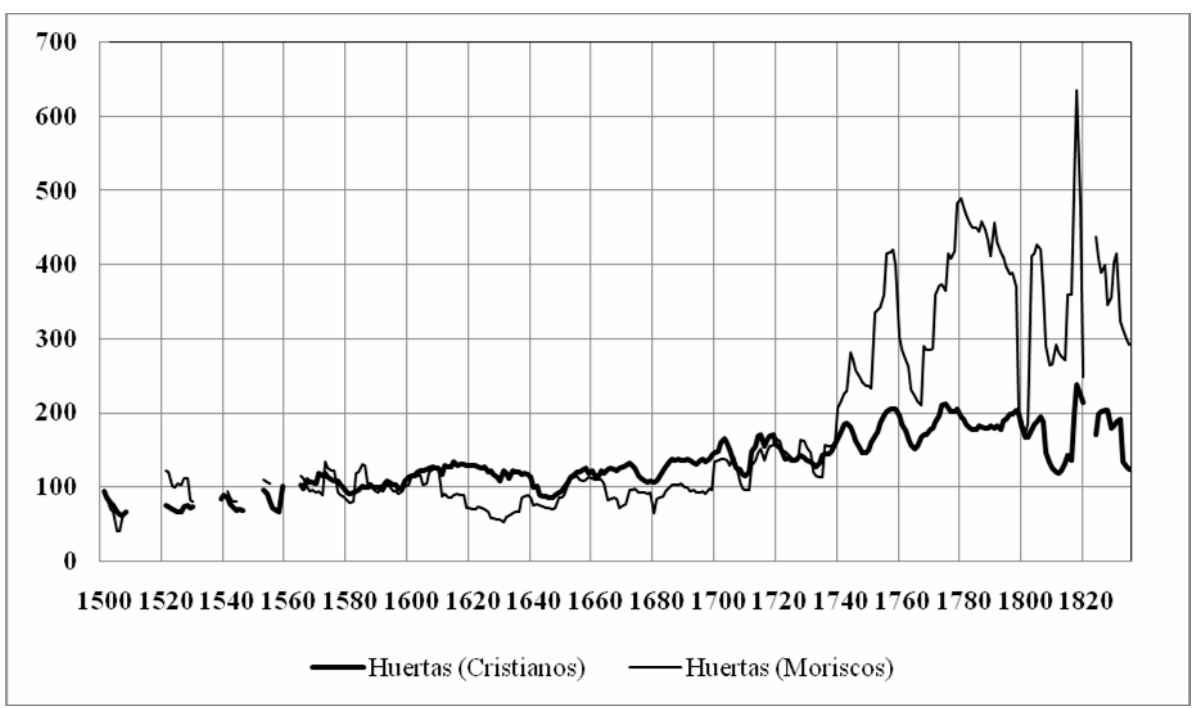


Gráfica 7. Evolución del diezmo mayor Índices. Base: 1585-1599=100. Llanuras Centrales

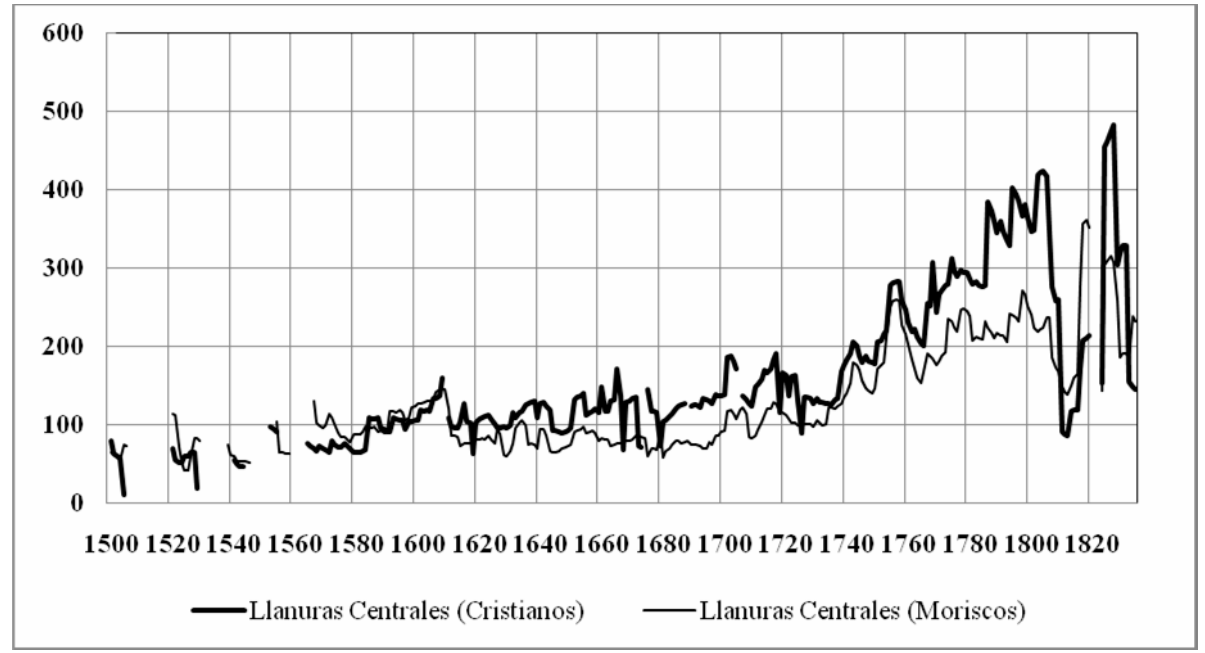

Gráfica 8. Evolución del diezmo mayor Índices. Base: 1585-1599=100. Montañas Septentrionales y Montañas Centrales

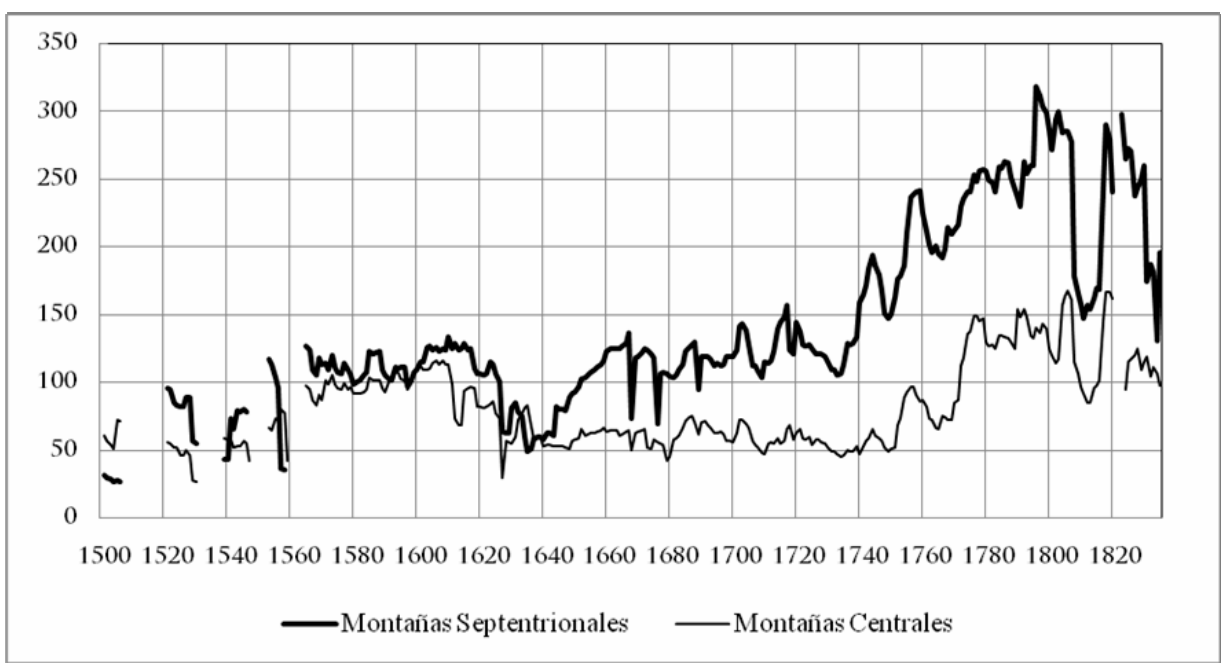


ritaria en la segunda macrocomarca y minoritaria en la primera, y esta diferenciación se aprecia con nitidez en la Gráfica 7. Si hasta 1609 la producción agraria de los dos conjuntos era parecida, a partir de la expulsión las Montañas septentrionales se despegaron de la otra macrocomarca que había sido mayoritariamente morisca.

La interpretación de las gráficas es delicada y se ha tenido que hacer teniendo en cuenta las características particulares de cada conjunto territorial. Es probable que la evolución agraria deducida de la recaudación decimal del arzobispado de Valencia pudiera interpretarse de otra manera, pero por razones de coherencia con el primer análisis demográfico y con el de la estructura de la propiedad, al que dedicaremos el siguiente apartado, creo que es la más verosímil. Como escribió James Casey, formulando una de las primeras interpretaciones de las consecuencias de la expulsión de los moriscos similar a la que ahora propongo, hace casi cuarenta años, «el campesino, después de la expulsión, se sustentaba mejor de una propiedad que se adaptaba, por primera vez, a la medida de su necesidad. (...) La influencia más decisiva era la de una estructura social estable, a base de una agricultura que, si no muy floreciente [Casey se refiere a los momentos inmediatamente posteriores a la expulsión], era al menos

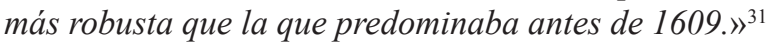

\section{LOS CAMBIOS EN LA ESTRUCTURA DE LA PROPIEDAD DE LA TIERRA}

Los estudios existentes sobre la propiedad de la tierra en las localidades moriscas antes y después de la expulsión han revelado que la propiedad morisca era, aunque con notables discrepancias según lugares, minifundista y con escasa concentración. Esta estructura cambió mucho con la repoblación cristiana, aunque también con importantes contrastes locales. Uno de los primeros estudios que pusieron de relieve esta característica fue el de Adelina Bataller sobre los pueblos de la comarca de la Safor regados por las aguas del río Vernissa, que eran Real, Benipeixcar, Benirredrà y los desaparecidos, por su integración en municipios más grandes, Beniopa, Benicanena y l'Alqueria Nova $^{32}$. La autora estudió la estructura de la propiedad agraria antes y después de la expulsión y sus resultados se extractan en la Tabla 2.

El predominio de la pequeña propiedad y la escasa concentración del año 1593 fueron sustituidos por una estructura, el año 1630, en la que las pequeñas propiedades retrocedieron sensiblemente, aumentando las medianas y las grandes. Este mismo fenómeno fue detectado por Santiago La Parra, muchos años después, en todo el territorio del ducado de Gandía, tanto el regado por el Vernissa como por el Serpis, como puede verse en la Tabla 3 .

31. CASEY, James: «Las consecuencias de la expulsión de los moriscos en la agricultura valenciana», III Congreso Nacional de Historia de la Medicina, Madrid: Sociedad Española de Historia de la Medicina, 1971, II, pp. 153-158.

32. BATALLER, Adelina: "La expulsión de los moriscos y su repercusión en la propiedad y en la población en la zona de los riegos del Vernisa”, Saitabi, Valencia, 1960, 10, pp. 81-100. 
Tabla 2

Estructura de la propiedad de la tierra en el área regada por el Vernissa (en tantos por cien)

\begin{tabular}{|c|c|c|c|c|}
\hline \multirow{2}{*}{ Extensión (hanegadas) } & \multicolumn{2}{|c|}{1593} & \multicolumn{2}{c|}{1630} \\
\cline { 2 - 5 } & Propietarios & Hanegadas & Propietarios & Hanegadas \\
\hline$\leq 10$ & 75 & 38 & 39 & 13 \\
\hline $10,1-30$ & 22 & 42 & 48 & 46 \\
\hline$>30$ & 3 & 20 & 13 & 41 \\
\hline
\end{tabular}

Tabla 3

Propiedad agraria media en el ducado de Gandía (en hanegadas)

\begin{tabular}{|l|c|c|}
\hline \multicolumn{3}{|c|}{ Área regada por la acequia del Vernissa } \\
\hline Lugaress & $\mathbf{1 5 9 3}$ & $\mathbf{1 6 3 0}$ \\
\hline Gandía & 12,26 & - \\
\hline Arrabal de Gandía & 5,76 & - \\
\hline Alcodar & 4,72 & 18,17 \\
\hline Alqueria Nova & 4,87 & - \\
\hline Alqueria de Martorell & 7,41 & 29,25 \\
\hline Beniopa & 7,91 & 13,59 \\
\hline Benipeixcar & 6,78 & 15,32 \\
\hline Benirredrà & 10,85 & 10,77 \\
\hline Real de Gandía & 8,25 & 21,29 \\
\hline \multicolumn{3}{|c|}{ Área regada por el río Serpis } \\
\hline Gandía & 12,65 & 18,69 \\
\hline
\end{tabular}

Con una sola excepción, la de Benirredrà, la propiedad media aumentó de forma muy significativa después de la repoblación, y todavía más espectaculares fueron los cambios en el parcelario, ya que la mayoría de los campos de los moriscos de la comarca, un 75 por 100 exactamente, no superaban la extensión de 4 hanegadas $(0,3 \mathrm{Ha})$ y esta proporción bajó al 33 por 100 después de la expulsión ${ }^{33}$. Estamos hablando de una de las comarcas más ricas del País Valenciano, en la que la agricultura de regadío era predominante. Si cambiamos de escenario y examinamos la estructura de la propiedad de la tierra en unos municipios de la comarca meridional valenciana del Bajo Segura, encontramos el mismo fenómeno, incluso más acusado. En este caso sólo se ha estudiado la propiedad morisca el mismo año de la expulsión, 1609, y no la establecida

33. LA PARRA LÓPEZ, Santiago: Los Borja y los moriscos (repobladores y «terratenientes» en la huerta de Gandia tras la expulsión de 1609, Valencia: Diputación Provincial, 1992, esp. p. 232. 
por los repobladores cristianos $^{34}$. La distribución de la propiedad de la tierra en cuatro pueblos de la comarca, Redován, Albatera, Coix y La Granja de Rocamora, se puede examinar en la Tabla 4.

Tabla 4

Estructura de la propiedad de la tierra en cuatro municipios moriscos del Bajo Segura (en tantos por cien)

\begin{tabular}{|c|c|c|c|c|c|c|c|c|}
\hline \multirow{2}{*}{$\begin{array}{c}\text { Extensión } \\
\text { (tahullas) }\end{array}$} & \multicolumn{2}{|c|}{ Redován } & \multicolumn{2}{c|}{ Albatera } & \multicolumn{2}{c|}{ Coix } & \multicolumn{2}{c|}{ La Granja } \\
\hline$\geq 1$ & Propietarios & Tahullas & Propietarios & Tahullas & Propietarios & Tahullas & Propietarios & Tahullas \\
\hline $1,1-2$ & 31,1 & 21,3 & 51,3 & 59,5 & 48,4 & 45,3 & 15,9 & 12,7 \\
\hline $2,1-3$ & 14,9 & 20,5 & 8,0 & 15,2 & 25,8 & 38,5 & 72,7 & 80,3 \\
\hline$>3$ & 13,5 & 39,4 & 0,0 & 0,0 & 2,1 & 5,6 & 2,3 & 8,3 \\
\hline
\end{tabular}

Especialmente en Albatera y la Granja de Rocamora la distribución de la propiedad de la tierra era casi igualitaria. Según este mismo autor, en las localidades cristianas de la misma comarca, Orihuela, Callosa de Segura, Almoradí, Catral y Guardamar, las dimensiones de la propiedad agraria eran muy superiores y existían acusadas diferencias entre un numeroso conjunto de pequeños propietarios y una cúspide social que poseía casi la mitad de la superficie cultivada. En el marquesado de Llombai, señorío situado en la Ribera Alta, de agricultura no tan rica como la de los pueblos examinados hasta ahora, las cosas no fueron muy diferentes, aunque la estructura de la propiedad instaurada con la repoblación cristiana no fue tan concentrada. En este caso, sin embargo, se ha podido estudiar la distribución de los cultivos, y las modificaciones que se produjeron pueden calificarse de espectaculares ${ }^{35}$. Esta información se puede ver en las Tabla 5.

Se ha de reconocer que en este territorio los cambios que tuvieron lugar en la superficie regada entre 1581 y 1699 no fueron tan importantes, pero así y todo se observa un claro aumento de la propiedad mediana y grande, por encima de las 10 hanegadas, equivalentes aproximadamente a 0,9 Ha. En la propiedad de secano, que no se reproduce para no alargar excesivamente este artículo, los cambios fueron más importantes, lo que parece corroborar la opinión de algunos publicistas del tiempo de la expulsión, como Bleda, que pensaban que los moriscos no cultivaban mucho el secano. Mucho más importantes fueron, como se ha dicho, los cambios en los cultivos, como puede verse en la Tabla 6 .

34. BERNABÉ GIL, David: «La Vega Baja del Segura en vísperas de la expulsión de los moriscos: estructura de la propiedad de la tierra», en Estructuras y regímenes de tenencia de la tierra en España, Madrid: Ministerio de Agricultura, Pesca y Alimentación, 1987, pp. 61-74. La tahúlla, medida de superficie muy variable según localidades, equivalía aproximadamente a $0,1 \mathrm{Ha}$.

35. ARDIT, Manuel: Creixement econòmic i conflicte social. La foia de Llombai entre els segles XIII I XIX, Catarroja-Barcelona: Afers, 2004, esp. pp. 68-70 y 110-115. 
Tabla 5

Estructura de la propiedad de huerta en el marquesado de Llombai antes y después de la expulsión de los moriscos (en tantos por cien)

\begin{tabular}{|c|c|c|c|c|}
\hline \multirow{2}{*}{ Extensión (hanegadas) } & \multicolumn{2}{|c|}{1581} & \multicolumn{2}{c|}{1699} \\
\cline { 2 - 5 } & Propietarios & Superficie & Propietarios & Superficie \\
\hline$<10$ & 61,7 & 33,4 & 35,8 & 10,8 \\
\hline$\geq 10,<20$ & 31,3 & 44,7 & 31,9 & 26,9 \\
\hline$\geq 20,<30$ & 4,4 & 10,8 & 16,5 & 23,4 \\
\hline$\geq 30,<40$ & 1,8 & 6,2 & 9,1 & 17,8 \\
\hline$\geq 40,<50$ & 0,4 & 2,2 & 4,2 & 10,8 \\
\hline$\geq 50$ & 0,4 & 2,7 & 2,5 & 10,3 \\
\hline
\end{tabular}

Tabla 6

Cultivos de huerta del marquesado de Llombai antes y después de la expulsión de los moriscos (en tantos por cien de la superficie cultivada)

\begin{tabular}{|l|c|c|}
\hline Cultivos & $\mathbf{1 5 8 1}$ & $\mathbf{1 6 9 9}$ \\
\hline Cereales & 86,8 & 32,5 \\
\hline Morera & 5,2 & 58,1 \\
\hline Viña & 3,0 & 0,9 \\
\hline Viña y cultivos asociados & 0,8 & 4,3 \\
\hline Higuera & 1,4 & - \\
\hline Higuera y cultivos asociados & 1,2 & - \\
\hline Olivo & 0,9 & 2,6 \\
\hline Olivo y cultivos asociados & 0,3 & 1,0 \\
\hline Algarrobo & 0,3 & 0,6 \\
\hline Naranjo & 0,1 & - \\
\hline
\end{tabular}

No creo que sea excesivo calificar estos cambios de revolucionarios. Entre 1581 y 1699 se pasó de una agricultura dominada por los cereales a otra de clara orientación comercial, en la que el cultivo hegemónico era la morera, alimento de los gusanos de seda, cuya producción se destinaba a las fábricas de Toledo y Valencia. El pequeño crecimiento de la viña, el olivo y el algarrobo es sólo aparente, ya que éstos, igual que el cereal, pasaron a cultivarse principalmente en el secano.

Las cosas no fueron iguales en todas partes. Es muy probable que en algunos lugares la agricultura morisca estuviese orientada al mercado, que la propiedad media fuese mayor y que la estructura social estuviese más diferenciada. Uno de estos casos fue el 
de la ciudad de Elche, en la que encontramos una realidad bien diferente ${ }^{36}$. En la Tabla 7 se reproduce la estructura de la propiedad agraria morisca a principios del siglo XVII.

Tabla 6

Estructura de la propiedad agraria morisca en Elche (1600-1609) (en tantos por cien)

\begin{tabular}{|c|c|c|}
\hline Tahullas & Propietarios & Extensión \\
\hline$<5$ & 33,8 & 3,7 \\
\hline $5-18,9$ & 39,8 & 14,6 \\
\hline $19-60,9$ & 18,5 & 24,4 \\
\hline $61-150,9$ & 4,9 & 21,0 \\
\hline$\geq 151$ & 3,0 & 36,3 \\
\hline
\end{tabular}

La información recogida en este último apartado es local e indudablemente incompleta, pero interpretada conjuntamente con la aportada en los anteriores indica que es difícil mantener la hipótesis de que la expulsión de los moriscos fue un grave obstáculo en el proceso de transición del feudalismo al capitalismo en el País Valenciano. Incluso se podría aventurar que los datos apuntan más bien en la dirección contraria. Es mucho todavía lo que habría que investigar para confirmar esta interpretación. Harían falta, entre otros, más estudios sobre la estructura de la propiedad morisca de la tierra y la instaurada después de la repoblación, con una cobertura geográfica más amplia. Haría falta también una explicación convincente de la peculiar estructura de la propiedad y de los cultivos de las localidades moriscas. Se argumenta a menudo que esto fue consecuencia de que en el proceso medieval de conquista y población los musulmanes vencidos quedaron arrinconados, aunque con excepciones, en las peores tierras. Pero hemos visto que estas características aparecen también en territorios que no se pueden considerar pobres, como la comarca de la Safor. Es probable que estas peculiaridades tengan también una explicación cultural que es difícil de intuir. Quizás la estructura clánica de la sociedad morisca, algo que de todos modos habría que demostrar, implicase algún obstáculo a la concentración de la propiedad y a la orientación comercial de la agricultura. Este artículo, igual que otras publicaciones anteriores en la misma línea, sólo ha pretendido incidir en la dificultad que hay en responsabilizar a la expulsión de los moriscos de un supuesto atraso económico valenciano, consecuencia del retroceso que aquélla implicó en su proceso de desarrollo capitalista.

36. SERRANO JAEN, Joaquim: De patricis a burgesos (les transformacions d'una oligarquía terratinent; Elx, 1600-1855), Alicante: Instituto de Cultura Juan Gil-Albert, 1995. Texto más completo el de la tesis doctoral inédita del autor, Estructures agràries al sud del País Valencià. Propietat, règim d'explotació $i$ distribució social de la terra a Elx. De la problemática morisca a la consolidació de la revolució burgesa (1600-1855), València, 1990, esp. pp. 147 y 148. 